\title{
Design and Simulation of Spoon Shaped Antenna using DGS
}

\author{
Vivek Kumar, D.K. Parsediya
}

\begin{abstract}
A planer spoon shaped antenna with defected ground structure (DGS) is designed and fabricated for wireless application. The proposed antenna design exhibits $1.6 \mathrm{GHz}$ bandwidth, 2.20dBi Avg. Gain and maximum return loss of -24.5dB, which offers better results in wideband application. The Proposed antenna structure is simulated by software CST MWS (CST Microwave Studio) version 2018 and later comparison results are also presented
\end{abstract}

Keywords: DGS, Bandwidth, Return loss, Avg. Gain, CST MWS.

\section{INTRODUCTION}

Microstrip antenna has fascinated lots of researchers in recent years. With the sudden boom in the field of wireless communication it draws the attraction in microstrip antenna. Several microstrip antenna designs with single feed wideband antenna have been proposed lately. Over the years many types of microstrip patch antennas were designed to reduce the requirement of number of antennas. Because of its low weight, low price and low maintenance, microstrip antennas have been always in demand [1, 2, 3]. There are various usage and advantages of using DGS, cross polarization and mutual coupling reduction etc. are few of them [4]. Capacitance and inductance are key parameters when it comes to characteristics of DGS, size of the defect and area is a significant reason which decides the value of such parameters [5].

In [2] the multiband monopole antenna with DGS (conventional) has been proposed which exhibits bandwidth and Avg. Gain around $1.4 \mathrm{GHz}$ and $1.75 \mathrm{dBi}$ respectively. Since in the wireless communication application, more bandwidth and gain are in demand. The proposed spoon shaped antenna offers the bandwidth of $1.6 \mathrm{GHz}$ and Avg. Gain of $2.20 \mathrm{dBi}$ respectively. Both of the performance parameters of proposed design are better as compare to the conventional one. For achieving the better performance, the conventional design is modified by introducing the small strip of size $5 \times 3 \mathrm{~mm}$ at the center of the spoon.

The wide bandwidth and small size are quality parameters which were emphasized in this particular paper. Proposed DGS structure not only improved the key parameters of the antenna but reduced the size as well. This proposed antenna was specially designed for wireless application where

Revised Manuscript Received on December 30, 2019.

* Correspondence Author

Vivek Kumar*, B.E., electronics and communication, ITM Gwalior. D.K. Parsediya, Assistant professor, MITS Gwalior

(C) The Authors. Published by Blue Eyes Intelligence Engineering and Sciences Publication (BEIESP). This is an open access article under the CC BY-NC-ND license (http://creativecommons.org/licenses/by-nc-nd/4.0/) wideband is the main requirement. DGS was implemented to improve the characteristics of antenna. DGS plays a important role in the improvement of the antenna results, before applying DGS antenna was operating with $\geq 10 \mathrm{~dB}$ return loss with negligible bandwidth [6, 7]. After introducing DGS on the ground surface of the antenna, it starts radiating at $2.7 \mathrm{GHz}$ with $1.6 \mathrm{GHz}$ bandwidth. By varying the size of the DGS it was found that parameters of antenna is changing at very fast rate, a maximum return loss of $-40 \mathrm{~dB}$ was also achieved by changing the size of the DGS.

\section{ANTENNA DESIGN}

Fig. 1 represents the geometry of proposed antenna, where the front, back and transparent views are shown by Fig. 1(i), Fig. 1(ii), Fig. 1(iii), respectively. The software CST MWS (CST Microwave Studio) version 2018 is used for the design of proposed antenna and its simulation. With the aim of higher bandwidth and gain the conventional design [2] is altered by proposing a small strip at the center of spoon.

The proposed microstrip antenna design encompasses the spoon shaped patch on the front and DGS at the back of printed circuit board (PCB). The design parameters of the patch and DGS are depicted in Fig. 1.The dimensions of all these parameters are in millimeter $(\mathrm{mm})$. For designing the values of these parameters are considered as; $R_{1}=11, R_{2}=7$, $\mathrm{W}_{1}=3, \mathrm{~W}_{2}=56, \mathrm{~W}_{3}=32.5, \mathrm{~L}_{1}=17.5, \mathrm{~L}_{2}=9, \mathrm{~L}_{3}=12.5, \mathrm{~L}_{4}=$ $37, \mathrm{P}=5, \mathrm{Q}=4, \mathrm{R}=11$, and $\mathrm{S}=24.5$.

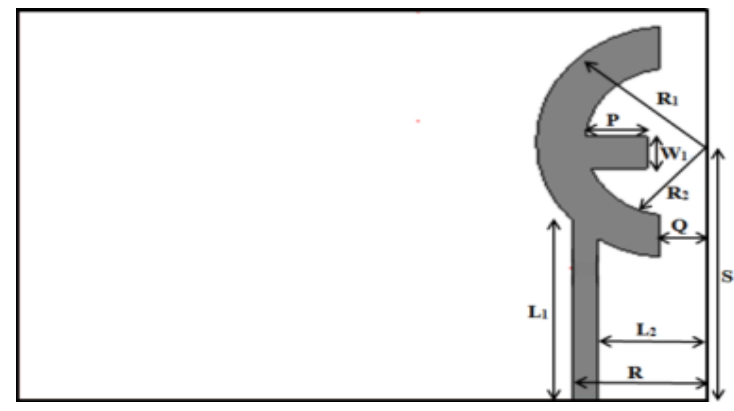

(i)

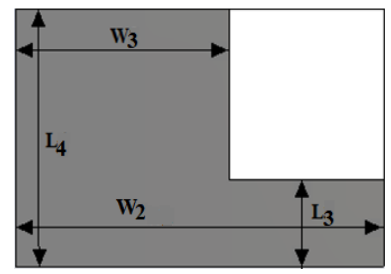

(ii)

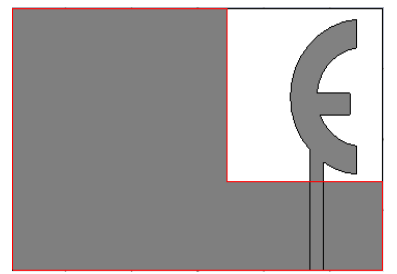

(iii)
Fig. 1 Geometry of the proposed antenna (i) Front, (ii) Back, (iii) Transparent view

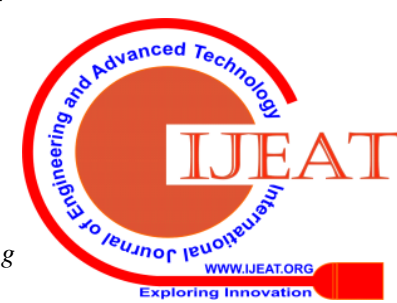


Radiation of the antenna mainly depends on the substrate (FR4) and its key parameters $(\varepsilon, \sigma, \mu)$.The thickness of substrate is $1.6 \mathrm{~mm}$. Bandwidth is directly related to thickness of the substrate and inverse relation with permittivity of the substrate $[8,9]$. In this research work, the substrate used has the dielectric constant $\left(\varepsilon_{\mathrm{r}}\right)$ is 4.3. FR4 (Lossy) substrate has been used for designing the antenna with parameters as mentioned above. In Fig. 2 represents the simulated results of the proposed antenna. In Fig. 2(i) three different cases of S-parameter are analyzed for different value of $\mathrm{R}_{1}$ (mainly $\mathrm{R}_{1}=11,12 \& 13$ ). In Fig. 2 (ii) the effect of variation of $R_{2}$ (mainly $R_{2}=6,7 \& 8$ ) on $S$-parameter is considered. In Fig. 2 (iii) depicts the effect of variation in ground plane on S-parameter. While in Fig. 2(iv) depicts the finalized S11 of proposed antenna. By Fig. 2, it can be clearly seen that the maximum reflection coefficient (S11) $-40 \mathrm{~dB}$, maximum bandwidth $1.8 \mathrm{GHz}$ and average realized Avg. Gain of $2.20 \mathrm{dBi}$ can be achieved.

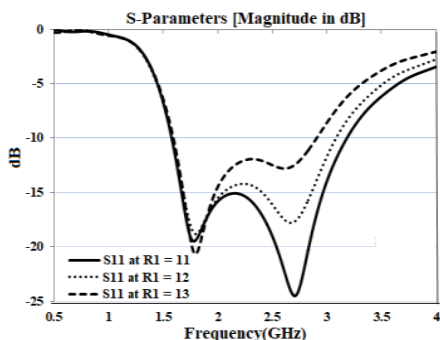

(i)

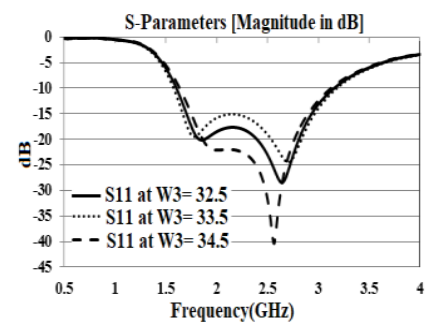

(iii)

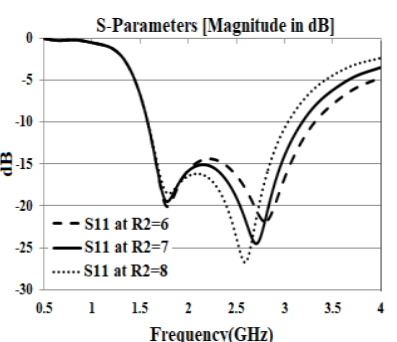

(ii)

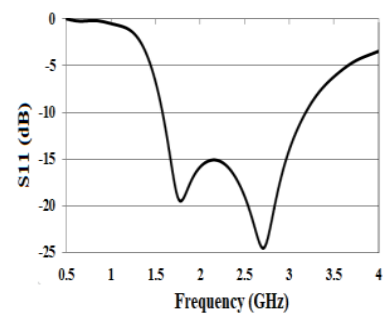

(iv)
Fig. 2: Reflection coefficient (S11) of the proposed antenna (i) by varying $R_{1}$ (ii) by varying $R_{2}$, (iii) by varying DGS ( $\mathrm{W}_{3}=32.5,33.5$ and $34.5 \mathrm{~mm}$ ) (iv) Finalized reflection coefficient (S11) of proposed antenna

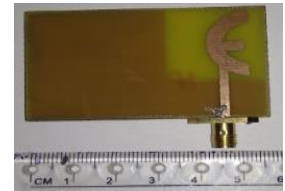

(i)

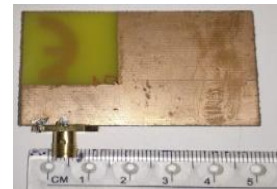

(ii)

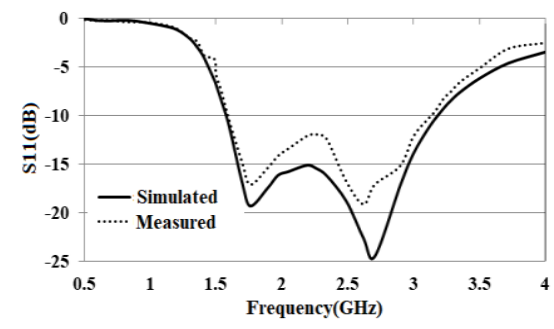

(iii)

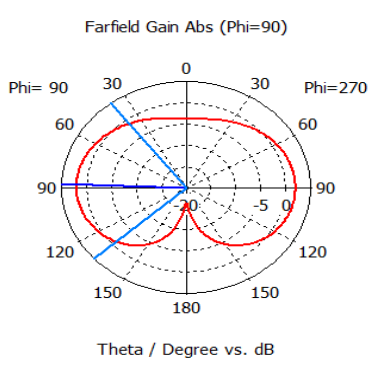

(a)

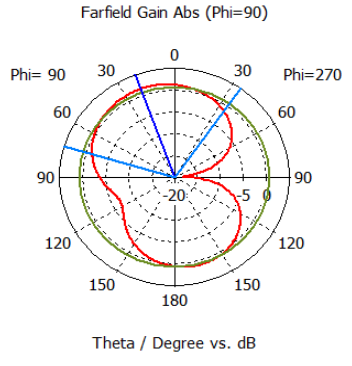

(b)

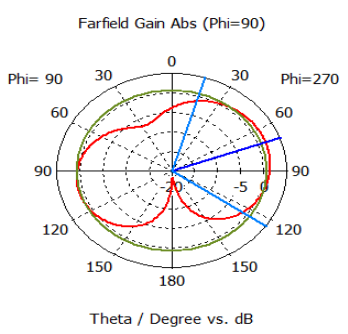

(c)

\section{(i) $1.8 \mathrm{GHz}$}

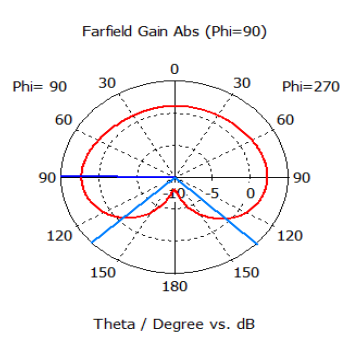

(a)

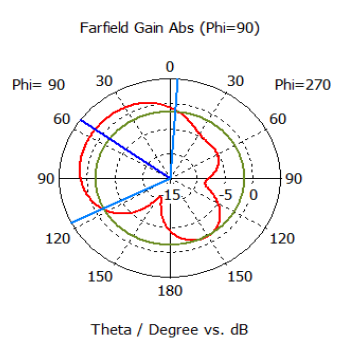

(b)

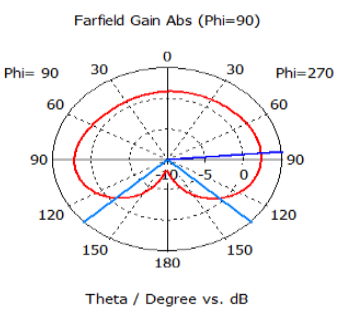

(c)

(ii) $2.8 \mathrm{GHz}$

Fig. 4: Simulated radiation patterns of the proposed antenna: (a) X-Y plane; (b) Y-Z plane; (c) X-Z plane at frequencies (i) 1.8 ,(ii)2.8GHz.

Fig.3 (i) \& (ii) depicts the photograph of fabricated front and back view of proposed antenna while Fig. 3(iii) depicts the simulated and measured S11 of proposed antenna. Fig.4 (i) \& (ii) depicts the radiation pattern of proposed antenna operating at frequencies 1.8 and $2.8 \mathrm{GHz}$ respectively. The gain at different frequencies is shown below in Fig. 5 . It exhibits the range of gain values from $1.65 \mathrm{dBi}$ at $1.5 \mathrm{GHz}$ to $2.63 \mathrm{dBi}$ at $3.3 \mathrm{GHz}$. Maximum value of Gain is around $2.45 \mathrm{dBi}$ at frequency $2.6 \mathrm{GHz}$

Fig. 3: Fabricated antenna and its result (i) Front view (ii) Back view (iii) Simulated and measured reflection coefficient (S11) 


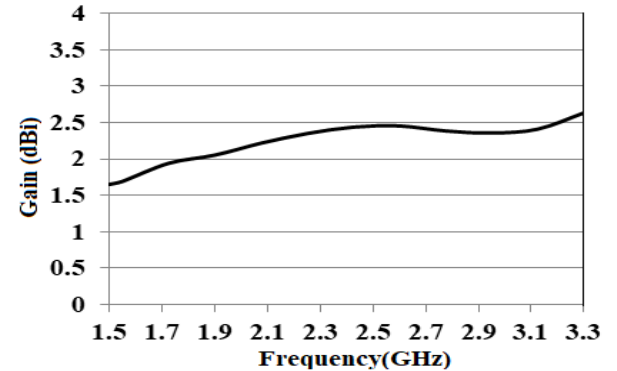

Fig.5: Gains of the proposed antenna

\section{RESULTS AND DISCUSSIONS}

The simulated and measured S-parameter of proposed antenna design are shown in Fig.4 (iii). By which it can be clearly observed that $S_{11}<-10 \mathrm{~dB}$ at two resonant frequencies $1.57 \mathrm{GHz}$ to $3.18 \mathrm{GHz}$. The proposed design offers the impedance bandwidth of nearly $67.78 \%$ with central frequency at $2.375 \mathrm{GHz}$. It also exhibits a range of gain value approximately from $1.966 \mathrm{~dB}$ to $2.246 \mathrm{~dB}$.

The Comparison between the proposed design and design given by [2] is shown in Table 1 . It perceived that S-parameter, gain and bandwidth of proposed design have refined as compare to the conventional design and it offers large operating range of frequencies over which the antenna works. The value of Bandwidth, Avg. Gain and S-parameter of the proposed design are $1.6 \mathrm{GHz}, 2.20 \mathrm{dBi}$ and $-24.5 \mathrm{~dB}$, respectively.

Table 1: Comparison between proposed design with [2]

\begin{tabular}{|c|c|c|}
\hline $\begin{array}{c}\text { Performance } \\
\text { Parameter }\end{array}$ & This Work & {$[2]$} \\
\hline Bandwidth & $1.6 \mathrm{GHz}$ & $1.4 \mathrm{GHz}$ \\
\hline Avg. Gain & $2.20 \mathrm{dBi}$ & $1.75 \mathrm{dBi}$ \\
\hline
\end{tabular}

\section{CONCLUSION}

The proposed antenna design is a low cost and highly effective antenna design for wideband application which offers the efficiency of $93 \%$ and bandwidth of $1.6 \mathrm{GHz}$. By varying the size of the DGS significant results could be achieved. This spoon shaped antenna is useful not only for wideband radiation but this antenna is efficient as well. This proposed antenna could be used in $\mathrm{L}$ and as well as $\mathrm{S}$ band applications as it has a wide bandwidth. Significant results could be achieved as it can be seen from the comparative results, indicates that the slight variation in the size and shape of the proposed antenna makes the commendable change in the results.

\section{REFERENCES}

1. Constantine A. Balanis, Antenna Theory and Design. John Wiley \& Sons, Inc., 1997..

2. Chan Hwang See, Raed A. Abd-Alhameed, Dawei Zhou, Ting Hee Lee, and Peter S. Excell, "A Crescent-Shaped Multiband Planar Monopole Antenna for Mobile Wireless Applications" IEEE antennas and wireless propagation letters, pp. 152-155, vol. 9, 2010.

3. David M. Pozar, "Microwave Engineering", 3rd Edition, John Wiley \& Sons, 2004.

4. W.L. Stutzman, G.A. Thiele, Antenna Theory and design, John Wiley \& Sons, 2nd Ed., New York, 1998.

5. AshwiniArya, M.V. Kartikeyan, A. Patnaik, "Efficiency Enhancement of Micro-strip Patch Radiator with Defected Ground Structure", International conference on microwave, pp. 729-731, 2008.
6. J.P. Geng, J.J. Li, R.H. Jin, S. Ye, X.L. Liang and M.Z. Li, "The Developments of Curved Micro-strip Radiator with Defected Ground Structure" Progress in Electromagnetic Research, PIER, Vol. 98, pp. 53-73,2009.

7. A. Dastranj, A. Imani, and M. Naser- Moghaddasi, "Printed wide-slotantenna for wideband application," IEEE Trans. Antennas Propag., vol.56, no. 10, pp. 3097-3102, Oct. 2008.

8. J.-Y. Jan and J.-W.Su, "Bandwidth enhancement of a printed wide-slotantenna with a rotated slot," IEEE Trans. Antennas Propag., vol. 53, no.6, pp. 2111-2114, Jun. 2005.

9. W.-L. Chen, G.-M.Wang, and C.-X. Zhang, "Bandwidth enhancementof a microstrip-line fed printed wide-slot antenna with a fractal-shapedslot," IEEE Trans. Antennas Propag., vol. 57, no. 7, pp. 2176-2179,Jul. 2009.

\section{AUTHORS PROFILE}

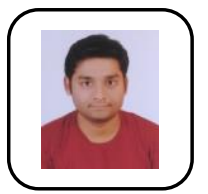

Vivek Kumar He received the B.E. degree in electronics and communication from ITM Gwalior in 2015.Currently he is pursuing M.E. degree in Communication Control and Networking from MITS Gwalior.

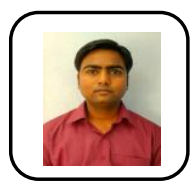

D.K. Parsediya He received the M.Tech. degree. He is currently an assistant professor in MITS Gwalior. 